IZA DP No. 9946

\title{
Profit Sharing and Peer Reporting
}

Jeffrey Carpenter

Andrea Robbett

Prottoy Akbar

May 2016 


\title{
Profit Sharing and Peer Reporting
}

\author{
Jeffrey Carpenter \\ Middlebury College \\ and IZA
}

Andrea Robbett

Middlebury College

Prottoy Akbar

University of Pittsburgh

\section{Discussion Paper No. 9946 \\ May 2016}

IZA
P.O. Box 7240
53072 Bonn
Germany

Phone: +49-228-3894-0

Fax: +49-228-3894-180

E-mail: iza@iza.org

\begin{abstract}
Any opinions expressed here are those of the author(s) and not those of IZA. Research published in this series may include views on policy, but the institute itself takes no institutional policy positions. The IZA research network is committed to the IZA Guiding Principles of Research Integrity.

The Institute for the Study of Labor (IZA) in Bonn is a local and virtual international research center and a place of communication between science, politics and business. IZA is an independent nonprofit organization supported by Deutsche Post Foundation. The center is associated with the University of Bonn and offers a stimulating research environment through its international network, workshops and conferences, data service, project support, research visits and doctoral program. IZA engages in (i) original and internationally competitive research in all fields of labor economics, (ii) development of policy concepts, and (iii) dissemination of research results and concepts to the interested public.
\end{abstract}

IZA Discussion Papers often represent preliminary work and are circulated to encourage discussion. Citation of such a paper should account for its provisional character. A revised version may be available directly from the author. 
IZA Discussion Paper No. 9946

May 2016

\section{ABSTRACT}

\section{Profit Sharing and Peer Reporting}

Despite the "1/N problem" associated with profit sharing, the empirical literature finds that sharing profits with workers has a positive impact on work team and firm performance. We examine one possible resolution to this puzzle by observing that, although the incentive to work harder under profit sharing is weak, it might be sufficient to motivate workers to report each other for shirking, especially if the workers are reciprocally-minded. Our model provides the rationale for this conjecture and we discuss the results of an experiment that confirms that profit sharing is most effective when peer reporting is possible.

JEL Classification: team production, profit sharing, peer reporting, reciprocity, experiment Keywords: $\quad$ C92, J30, D20, M52

Corresponding author:

Jeffrey Carpenter Department of Economics

Middlebury College

Middlebury, VT 05753

USA

E-mail: jpc@middlebury.edu 


\section{Introduction}

Empirical studies consistently find that profit sharing has a positive effect on worker produc-

tivity despite the fact that workers receive just a $\frac{1}{N}$ th share of their incremental output, surely not enough to compensate for the additional effort, especially when the size of the workforce, $N$, is large (Weitzman and Kruse, 1990; Bhargava, 1994; Hansen, 1997). According to Kruse (1992), this phenomenon has puzzled economists since profit sharing was first conceived during the industrial revolution. We examine one possible resolution to the puzzle by noticing that, although the incentive to work harder under profit sharing is weak, it might be sufficient to motivate workers to monitor each other and report shirkers, especially if the workers are reciprocally-minded (as discussed in Freeman et al., 2010).

There is scant evidence that profit sharing leads to peer reporting and better firm performance because it is hard to observe peer reporting, especially if it is informal, and even harder to directly link reporting behavior to work team productivity. Indeed, working within these limitations, Knez and Simester (2001) offer one of the most convincing accounts and yet they can only show that monthly bonuses (with incentives similar to profit sharing) are associated with teams in the airline industry being more likely to meet productivity goals and, based on anecdotal manager interviews, that "mutual monitoring" has some role. Focusing more on mutual monitoring, Welbourne (1995) surveyed workers in firms implementing gain sharing programs and found that workers reported monitoring their peers more closely when the gain sharing program instilled a sense of procedural justice. Unfortunately, this study cannot assess the direct causal effect of profit or gain sharing on the propensity to report coworkers and is silent on the important link between reporting and team performance.

Despite the ability to use experimental methods to observe and tease apart the causal impact of profit sharing on team performance, there are, to our knowledge, no experiments that test our hypothesis directly. Of course, there is now a large experimental literature on mutual monitoring in public goods games (Chaudhuri, 2011) and there is another large literature showing that reciprocal workers exchange "gifts" with their managers (Charness and Kuhn, 2011) and yet there are few experiments linking profit sharing or peer reporting to worker or team performance. Considering profit (or gain) sharing Nalbantain and Schotter (1997) examine 
various group incentive schemes and find that shirking does happen but not right from the start and that the shirking can be attenuated to some extent by manager monitoring or inter-team tournaments. Considering peer reporting, while our focus is on the effect of peers reporting shirkers to the manager, Corgnet (2012) finds that peer's assessments of each other if used to allocate a surplus reduces team performance, perhaps because the evaluations attenuate the intrinsic motivation to do the real effort task. Interestingly, what is similar to our study is the fact that social preferences seem to play a dominant role in how one assesses the performance of one's peers.

The model in the next section provides the rationale for our conjecture that the effect of profit sharing on worker effort is greatest when peer reporting is possible. While the theory builds on important contributions such as the model of peer monitoring in Kandel and Lazear (1992) or the one of altruistic workers in Rotemberg (1994), what differs is that we focus on inter-worker reciprocity and peers reporting shirking co-workers to a manager rather than disciplining each other directly, a method of punishment often discouraged in the workplace. We show that, although profit sharing may not be a strong enough incentive to work hard by itself (Holmstrom, 1982), it might suffice to encourage reciprocity-minded peers to report free riders because of the cost imposed on them when others shirk. And, when this occurs, teams with peer reporting and profit sharing will work harder than those with profit sharing (or peer reporting) alone.

In the sections that follow the model, we describe the results of an experiment. In the experiment, workers are randomly sorted into four conditions that vary our two treatment variables, profit sharing and peer reporting. Each period, workers earn a fixed wage plus a share of the surplus generated by the team if profit sharing is implemented. Each firm has a manager, who receives only a noisy signal of each worker's chosen effort and can dole out punishments by fining workers. At the end of each period, workers (in all conditions) see the anonymized efforts chosen by the other workers in the team and can report any other worker (if peer reporting is allowed). Comparing the four conditions, as predicted, we find that effort increases when workers share in firm profits and is highest when profits are shared and workers can report shirking co-workers. Without profit sharing, we find that peer reporting, by itself, cannot sustain higher efforts. We report evidence that workers who share in profits are more 
willing to (accurately) report shirkers, that managers rely heavily on worker reports when doling out punishments, and that punishments are directed toward shirkers with significantly greater accuracy in the treatment with both profit sharing and peer reporting. Further underlining the importance of accurately directing fines toward those workers who were actually shirking, we find that fines motivate shirkers to provide more effort in subsequent periods, but that misdirected fines can have a strong demotivating effect on previously hardworkers. We therefore find strong evidence to support the claim of Kandel and Lazear (1992), among others, that much of the effectiveness of profit sharing incentives results from workers with better information about their individual co-workers' efforts helping to enforce productivity norms.

\section{Conceptual framework}

We model the provision of effort by borrowing complementary aspects of the existing theoretical literature (e.g., Kandel and Lazear, 1992; Banerjee et al., 1994; Rotemberg, 1994; Besley and Coate, 1995; Carpenter et al., 2009). Consider first the case in which the "manager" offers a common fixed wage, $w$, to the workers of her firm who are indexed $i=1 \ldots N$ and whose marginal productivity is constant at $q$ units of output per unit of effort. The effort provided by the $i$ th worker, denoted $e_{i}$, is increasingly costly to provide (i.e., $c_{i}\left(e_{i}\right)>0$ and $c_{i}^{\prime}\left(e_{i}\right)>0$ ) and this cost is individual-specific in that some workers might be intrinsically motivated by the job (Benabou and Tirole, 2003) or others may seek to live up to the expectations of the firm (Akerlof and Kranton, 2005). The most efficient worker effort equates $q=c_{i}^{\prime}\left(e_{i}\right)$ when effort costs are convex or chooses the minimum worker effort when effort costs are linear and $c_{i}^{\prime}\left(e_{i}\right)>q$.

Consistent with the "lighthouse" models of monitoring and effort provision (Shapiro and Stiglitz, 1984), suppose the manager receives a signal about the performance of each worker. Specifically, suppose $0<p\left(e_{i}, \bar{e}, R_{i}\right)<1$ is the probability that the manager receives a signal that worker $i$ has shirked. This probability is determined by how hard the employee works (such that $\left.p_{e}\left(e_{i}, \bar{e}, R_{i}\right)<0\right)$, the level at which the "effort norm," $\bar{e}$, is set within the firm and the number of performance reports, $R_{i}=\Sigma r_{j i}$, that the manager receives from $i$ 's co-workers (such that $\left.p_{R}\left(e_{i}, \bar{e}, R_{i}\right)>0\right)$. To fix ideas using the simplest form of signaling technology, suppose 
that $p=f\left(e_{i}\right)+g\left(\bar{e}, R_{i}\right)$. In other words, the probability of being identified as a shirker is an additively separable function of the likelihood that the manager independently suspects the worker of shirking $\left(f(e)\right.$, where $\left.f_{e}(e)<0\right)$ and the peer reports that the manager receives about the worker $\left(g\left(\bar{e}, R_{i}\right)\right.$, where $\left.g_{R}\left(\bar{e}, R_{i}\right)>0\right)$, which depend on the workplace norm, $\bar{e}$. We note that an alternative specification in which the manager places more weight on reports that reinforce her own signal only strengthens the main insights of this model.

To begin, we assume that workers are unable to supplement the manager's signal by reporting their co-workers, and that $R_{i}=0$. In this setting, suppose that the fine imposed by the manager on shirkers is just $F$. Then workers maximize utility

$$
U_{i}=w-c_{i}\left(e_{i}\right)-p\left(e_{i}, \bar{e}, R_{i}\right) F
$$

by choosing the appropriate effort level. Here the first order condition is straightforward:

$$
-p_{e}\left(e_{i}, \bar{e}, R_{i}\right) F=c_{i}^{\prime}\left(e_{i}\right)
$$

and in the case of convex effort costs $\left(c_{i}^{\prime \prime}\left(e_{i}\right)>0\right)$ and a sufficiently large fine, workers are incentivized to provide enough effort to reasonably avoid the expected punishment imposed on shirkers. However, the effort provided in equilibrium will be suboptimal as long as $-p_{e}\left(e_{i}, \bar{e}, R_{i}\right) F<q$, that is as long as shirking has a smaller expected marginal cost to the worker than to the firm. If the cost of effort is linear, $c_{i}^{\prime \prime}\left(e_{i}\right)=0$, and sufficiently large, workers stubbornly provide no effort because it is too costly to avoid the expected fine (i.e., $\left.-p_{e}\left(e_{i}, \bar{e}, R_{i}\right) F<c_{i}^{\prime}\left(e_{i}\right)\right)$.

Now suppose the manager has decided to share profits with her workers. In this case, workers produce $q \sum e_{j}$ units of output collectively and in the simplest case each worker receives a share, $s<1 / N$, of this surplus. ${ }^{1}$ The worker's utility becomes,

$$
U_{i}=w+s\left(q \sum e_{j}\right)-c_{i}\left(e_{i}\right)-p\left(e_{i}, \bar{e}, R_{i}\right) F
$$

and the first order condition for workers is altered slightly:

$$
(s \times q)-p_{e}\left(e_{i}, \bar{e}, R_{i}\right) F=c_{i}^{\prime}\left(e_{i}\right)
$$

\footnotetext{
${ }^{1}$ Note that our results will not depend on whether we model the sharing of gains or profits. With this in mind, we opt to use gain sharing because it is simpler and it parallels the public goods literature.
} 
For convex effort costs, workers are incentivized to provide more effort than in the fixed wage case, where fine avoidance was the only incentive to work. If the share of surplus is small, however, then workers may still under-provide effort. If we assume that costs are linear, there will be two types of workers: those for whom working hard is relatively costly and therefore their share of the marginal benefit, $s \times q$, will not be enough to compensate them for the additional effort (i.e., they face the familiar " $\frac{1}{N}$ problem"), and those for whom the costs are relatively low and the profit share pushes them over the effort provision threshold. On average, one would see an increase in effort.

Lastly, in the spirit of the contributions listed above that model the workplace using social preferences, we consider what happens when "reciprocal" workers monitor and report each other. As is now standard, we assume that, although workers can monitor and report shirkers to the manager, their reports are not contractible in the standard sense because the reports are unverifiable. Instead, we see that, because shirkers impose monetary costs on them (i.e., their proceeds from firm profits are lower because of shirking), reciprocal workers have an incentive to report co-workers who do not perform up to the standard. What is important here is that, while the worker's share of the profits is not generally incentive enough to provide much more effort on its own, in a workplace with sufficiently reciprocal employees the incentive can be enough to promote peer reporting, which, in turn, leads to higher provided effort. In other words, the effect of profit sharing is magnified when reciprocal workers have a means of improving the manager's signal and increasing the likelihood that shirkers will be fined.

To see this logic, consider the cost imposed by a shirking worker on his fellow employees. This cost is a simple function of the rate at which any worker gains from a co-worker's effort and the difference between the offender's effort and the workplace norm: $\varsigma_{j}=s q\left(\bar{e}-e_{j}\right)$. Now suppose that the parameter $\lambda_{i} \geq 0$ represents worker $i$ 's reciprocity motive, which causes $i$ to value $j$ 's effort generously when $j$ conforms to the norm and negatively if he falls short (a la Rabin, 1993). We assume that the following term enters into $i$ 's utility function for each co-worker $j: \lambda_{i} \varsigma_{j} r_{i j}$, where $r_{i j}$ is the report $i$ sends to the manager regarding $j$. In other words, when worker $i$ monitors $j$, he compares his effort to the norm and gains positive utility from reporting him as a shirker but negative utility from reporting a hardworking co-worker. Reporting, however, comes at a cost, $t\left(r_{i j}\right)$, which is increasing and convex. Lastly, worker $i$ has 
to be mindful of not shirking the standard himself, the cost of which is captured in $p\left(e_{i}, \bar{e}, R_{i}\right)$. Putting this all together, we have:

$$
U_{i}=w+s\left(q \sum e_{i}\right)+\sum_{j \neq i}\left[\lambda_{i} \varsigma_{j} r_{i j}-t\left(r_{i j}\right)\right]-c_{i}\left(e_{i}\right)-p\left(e_{i}, \bar{e}, R_{i}\right) F .
$$

This final case is a bit more complicated because workers optimize over both effort and reporting but the first order conditions are intuitive. Considering reporting first, the condition $\frac{\partial U_{i}}{\partial r_{i j}}=\lambda_{i} s q\left(\bar{e}-e_{j}\right)-t_{r}\left(r_{i j}\right)=0$ indicates that enough reporting will take place to balance the marginal cost of doing so against the marginal (reciprocal) benefit, an amount which will be non-zero when co-workers exert effort below the workplace norm, given the invocation of social preferences. To see how worker $i$ 's report of $j$ responds to $e_{j}$, we take the derivative of the equilibrium condition with respect to $e_{j}: \frac{d r_{i j}^{*}}{d e_{j}}=\frac{-\lambda_{i} s q}{t_{r r}\left(r_{i j}\right)}$. Given the convexity of reporting costs $t\left(r_{i j}\right)$, we see that $\frac{d r_{i j}^{*}}{d e_{j}}<0$ when profits are shared $(s>0)$ and workers are reciprocal $\left(\lambda_{i}>0\right)$ and thus the number of peer reports a worker receives is negatively associated with his effort (i.e., $\left.d R_{i} / d e_{i}<0\right)$. Importantly, note that as the worker's share of the surplus, $s$, approaches zero, the incentive to report one's co-worker collapses. Hence, the model predicts that peer reporting will have no effect when wages are fixed, since workers should never choose to report.

Circling back to effort, the first order condition is the same as in the profit sharing case above, $(s \times q)-p_{e}\left(e_{i}, \bar{e}, R_{i}\right) F=c_{i}^{\prime}\left(e_{i}\right)$, although optimizing workers now put forth more effort to account for the increased chance of getting caught shirking by their reciprocal peers. To see this more clearly, we note that the first order condition implies that effort will increase as the responsiveness of the signal to effort, $p_{e}\left(e_{i}, \bar{e}, R_{i}\right)$, becomes more strongly negative. In the absence of peer reporting or profit sharing, $R_{i}\left(e_{i}\right)=0$ so $p=\left(e_{i}\right)+g(0)$ and $p_{e}=f_{e}(e)$. As demonstrated above, when profits are shared and reciprocal peers can report their co-workers, $d R_{i} / d e_{i}<0$ and thus $p=f\left(e_{i}\right)+g\left(\bar{e}, R_{i}(e)\right)$, yielding $p_{e}=f_{e}(e)+g_{R}\left(\bar{e}, R_{i}(e)\right) R_{e}(e)$. Given that $g_{R}\left(\bar{e}, R_{i}(e)\right)>0$ by initial assumption and $R_{e}(e)<0$ by the preceeding paragraph, we see that $p_{e}$ becomes more strongly negative and conclude that worker efforts will be greater in the presence of both profit sharing and peer reporting. ${ }^{2}$

In sum, this simple social preference-based model of monitoring in the workplace provides the logic on which we base the experiment described in the next section. As is now standard

\footnotetext{
${ }^{2}$ As noted above, if the manager's independent signal $f$ and her interpretation of the reports $g$ positively interact, then this only strengthens the claim.
} 
(Shapiro and Stiglitz, 1984), in the absence of reciprocity workers are compelled to work only if the fear of being punished by the manager is credible. Also, as first pointed out by Holmstrom (1982), transferring residual claimancy to the team, by itself, is unable to fully incentivize a team of workers to not shirk because the fractional share of one's own output is never enough to justify the cost, especially when one can free ride on others. And yet, the empirical literature referred to above suggests that profit sharing and residual claimancy can have strong motivating effects on workers. To solve this puzzle, we notice that, while just a share of one's marginal product may not be enough to justify the additional effort, the fact that shirkers deprive this benefit to reciprocal co-workers can be enough to make them retaliate, in this case by "tattling" to the manager. ${ }^{3}$ Thus, independent of the cost structure, our model predicts that: 1) fixed wage compensation will generate the lowest efforts, regardless of whether workers can monitor and report, since they have no incentive to report shirkers; 2) profit sharing incentives will increase effort a bit on average; and 3) effort will be highest when profit sharing is combined with peer reporting.

\section{Experimental design}

\subsection{Protocol}

Overall, 264 students participated in the experiment. Upon arriving to the lab, participants were told that they were taking part in experiment studying interactions in an office environment. Participants were randomly matched into groups, or "firms," of four people each and randomly assigned a role of either "worker" or "manager," such that each firm was composed of one manager and three workers. The workers' decision involved choosing an effort level and, in some conditions, choosing whether to report co-workers to the manager for shirking. The manager's decision involved choosing whether to punish the workers. Participants interacted in the same group of four for all ten periods of the experiment, plus a five period practice round. The number of periods was common knowledge. The subjects interacted only through the experimental software z-Tree (Fischbacher, 2007) and were recruited to the lab in large

\footnotetext{
${ }^{3}$ Put more simply, notice that as the worker's share of profits, $s$, goes to zero, reporting to the manager collapses.
} 
groups (typically 20 or 24 students) so that they would be unable to guess which other three individuals were in the same firm.

We use a $2 \times 2$ between-subjects experimental design, depicted in Table 1 , which allows us to independently vary whether workers share in the firm profits and whether workers monitor and report their co-workers. At least three sessions were conducted under each of the four treatment conditions. ${ }^{4}$ The remainder of section 3.1 describes the baseline game that all subjects experience, which is the same as the Fixed Wage condition. The following section (3.2) describes our treatment variations.

Table 1: Treatment Conditions

\begin{tabular}{|c|c|c|c|}
\hline & & \multicolumn{2}{|c|}{ Profit Sharing } \\
\hline & & No & Yes \\
\hline \multirow{2}{*}{ Reporting } & No & $\begin{array}{l}\text { Fixed Wage }(F W) \\
16 \text { Firms }(\mathrm{N}=64)\end{array}$ & $\begin{array}{l}\text { Profit Sharing }(P S) \\
16 \text { Firms }(\mathrm{N}=64)\end{array}$ \\
\hline & Yes & $\begin{array}{l}\text { Fixed Wage \& Peer Reporting }(F W \mathscr{G} P R) \\
\qquad 16 \text { Firms }(\mathrm{N}=64)\end{array}$ & $\begin{array}{c}\text { Profit Sharing \& Peer Reporting }(P S \& P R) \\
18 \text { Firms }(\mathrm{N}=72)\end{array}$ \\
\hline
\end{tabular}

In each period, workers receive a Fixed Wage of 50 Experimental Dollars $(\mathrm{E} \$)$ and independently choose how much effort to exert for the period. Their effort level can be any integer from 1 to 8 and each unit of effort costs the worker $\mathrm{E} \$ 5$ (and increases the firm profits by $\mathrm{E} \$ 25$ ). In other words, the payoff (per period) for worker $i$ is just $\pi_{i}=w_{W}-5 e_{i} .{ }^{5}$ After all three workers have chosen their effort level, the workers see the effort chosen by each of their co-workers. The order in which worker efforts appear to the co-workers is randomized each period, so that participants cannot track workers' behavior across periods. We chose to give workers a fixed wage, rather than allowing the manager to choose worker wages, to limit reciprocity with the manager and focus on reporting. This "jibes" better with Section 2 in which

\footnotetext{
${ }^{4}$ For three of the four conditions, we conducted three sessions each and all sessions had 20 or 24 participants. In the PS\&PM condition, we conducted an extra session of 16 people, since only 8 participants showed up to one of the sessions. One session of each condition was conducted at Middlebury College and the remaining sessions were conducted at the Economic Research Laboratory at Texas A\&M.

${ }^{5}$ We choose linear effort costs for two reasons. First, it makes the payoffs and decision problem much simpler for the subjects to understand. Second, it ensures that the payoff-maximizing strategy for each worker (i.e., in the absence of reciprocal preferences) is to choose $e_{i}=1$ across all treatments. In other words, the linear costs work against the emergence of treatment differences and thus strengthens the finding if such differences do emerge.
} 
there is no gift exchange and also ensures that workers will receive identical base wages across all four treatment conditions. In short, because the evolution of the wage is not our focus, we control for this aspect of employment.

In the baseline, Fixed Wage, version of the game, the managers receive all of the firm's profits, which are equal to the return on the effort chosen by the three workers in the firm minus the wages paid. The manager payoff is given by: $\pi_{M}=w_{M}+25\left(\sum e_{i}\right)-3(50)$, where the manager's wage, $w_{M}$, is set to 100 to ensure that participants do not earn negative payoffs. Toward the end of each period, the managers are able to fine as many of the workers in their firm as they choose. The fine reduces the worker's payoff by $\mathrm{E} \$ 20$ and costs the manager $\mathrm{E} \$ 5$ for each instance.

While the workers have complete information about the effort levels chosen by their coworkers, the managers only receive a noisy signal of each individual's effort. Toward the end of each period, managers see each worker's ID number (which is randomly reassigned each period) and may see a "low effort flag" beside any or all workers' IDs. As in Section 2, flags are weakly correlated with worker effort. Specifically, the probability that worker $i$ is flagged is given by $\operatorname{Prob}(\text { flagged })_{i}=0.53-0.03 e_{i}$. It is emphasized both in the instructions and on the manager's screen that workers who put in lower effort are more likely to be flagged but that high effort workers may be wrongly flagged and that low effort workers may go unflagged. A table indicating the likelihood of a worker being flagged for each possible effort he or she could have chosen is presented in the instructions and also appears on the managers' screens while they are viewing the flags. The specific signal technology was chosen so that a worker who fully shirks would be flagged with probability $1 / 2$ and that even a worker who exerts high effort is flagged regularly (nearly $3 / 10$ ths of the time). Therefore, this noisy signal alone may not allow managers to accurately direct punishment without additional information from the workers.

At the end of the period, after the manager has chosen whether to fine any of his or her workers, the managers learn the actual effort of each worker alongside the flag information and their fining choices. This information was given in order to provide complete feedback for the managers regarding the signal quality of the flag and the veracity of worker reports. Workers learn whether they have been fined or not but do not know the fates of their co-workers. In addition, all participants played an unpaid 5-period practice round of this baseline game (with 
no profit sharing or peer reporting) before being assigned to one of the four treatment conditions described in Section 3.2.

\subsection{Treatment Variations}

As described in Table 1, sessions differed in whether workers received only a fixed wage (Fixed Wage treatments) or also shared in firm profits (Profit Sharing treatments) and also differed in whether or not participants could report their co-workers to the manager for putting in "low effort" (Peer Reporting treatments).

In the two Fixed Wage treatments, worker and manager payoffs are as described above. Specifically, workers are paid a fixed wage of $\mathrm{E} \$ 50$ and it costs them $\mathrm{E} \$ 5$ for each unit of effort provided. Managers are paid a fixed wage of $\mathrm{E} \$ 100$ and receive all of the firm profits, which are equal to $\mathrm{E} \$ 25 \times \sum e_{i}-3(50)$. To ensure that the incentives are clear to the participants, we present them in the tabular form shown in the first two panels of Figure 1. The worker payoff table (panel 1) shows the fixed wage minus the cost of effort for each effort level the worker could choose, and was always displayed to the workers as they chose their effort levels. The manager payoff table (panel 2) shows the fixed wage plus firm profits for each total effort level the three workers in the firm could choose.

In the two Profit Sharing treatments, each worker receives a share, $s=0.12$, of the firm's profits, in addition to the fixed wage of $\mathrm{E} \$ 50$. Thus, a worker's payoff depends not only on his or her own effort choice, but the effort choices of the two co-workers. To illustrate to the participants how the worker's payoffs depend on each group member's effort, participants are presented with the payoff table displayed in the third panel of Figure 1, which also appeared on the workers' screens as they are making their effort choices. The payoff table illustrates the social dilemma (or $\frac{1}{N}$ problem) faced by workers in the Profit Sharing treatments. As the workers increase their own effort, their payoffs decrease by $\mathrm{E} \$ 2$ regardless of what their co-workers choose (as seen by looking across any row in the table). Thus, the workers still have a dominant strategy to fully shirk. However, as a worker in the firm increases his or her effort, the payoffs of the other two workers increase by $\mathrm{E} \$ 3$ each, as seen by looking down any column in the table. Even disregarding the manager's payoffs, the most efficient outcome for the workers occurs when everyone works as hard as possible. In this case, worker payoffs are 
approximately $78 \%$ higher than the dominant strategy outcome. ${ }^{6}$

The manager in the Profit Sharing treatments receives the remaining $64 \%$ of the firm's profit and, as in the Fixed Wage treatment, also receives a fixed wage of $\mathrm{E} \$ 100$. The profits for these managers from each total effort level in the firm were presented to the participants using the image displayed in the fourth panel of Figure 1.

1) Fixed Wage, Worker Payoffs:

\begin{tabular}{|r|r|r|r|r|r|r|r|}
\hline Your Effort \\
\hline $\mathbf{1}$ & $\mathbf{2}$ & $\mathbf{3}$ & $\mathbf{4}$ & $\mathbf{5}$ & $\mathbf{6}$ & $\mathbf{7}$ & $\mathbf{8}$ \\
\hline 45 & 40 & 35 & 30 & 25 & 20 & 15 & 10 \\
\hline
\end{tabular}

2) Fixed Wage, Manager Payoffs: Total Effort by Workers

\begin{tabular}{|r|r|r|r|r|r|r|r|r|r|r|r|r|r|r|r|r|r|r|r|r|r|}
\hline $\mathbf{3}$ & $\mathbf{4}$ & $\mathbf{5}$ & $\mathbf{6}$ & $\mathbf{7}$ & $\mathbf{8}$ & $\mathbf{9}$ & $\mathbf{1 0}$ & $\mathbf{1 1}$ & $\mathbf{1 2}$ & $\mathbf{1 3}$ & $\mathbf{1 4}$ & $\mathbf{1 5}$ & $\mathbf{1 6}$ & $\mathbf{1 7}$ & $\mathbf{1 8}$ & $\mathbf{1 9}$ & $\mathbf{2 0}$ & $\mathbf{2 1}$ & $\mathbf{2 2}$ & $\mathbf{2 3}$ & $\mathbf{2 4}$ \\
\hline $\mathbf{2 5}$ & $\mathbf{5 0}$ & $\mathbf{7 5}$ & 100 & 125 & 150 & 175 & 200 & 225 & $\mathbf{2 5 0}$ & $\mathbf{2 7 5}$ & $\mathbf{3 0 0}$ & $\mathbf{3 2 5}$ & $\mathbf{3 5 0}$ & $\mathbf{3 7 5}$ & $\mathbf{4 0 0}$ & $\mathbf{4 2 5}$ & $\mathbf{4 5 0}$ & $\mathbf{4 7 5}$ & 500 & 525 & 550 \\
\hline
\end{tabular}

\begin{tabular}{l} 
3) Profit Sharing, Worker Payoffs: \\
\cline { 2 - 10 } \\
\cline { 2 - 10 }
\end{tabular}

4) Profit Sharing, Manager Payoffs:

Total Effort by Workers

\begin{tabular}{|r|r|r|r|r|r|r|r|r|r|r|r|r|r|r|r|r|r|r|r|r|r|}
\hline $\mathbf{3}$ & $\mathbf{4}$ & $\mathbf{5}$ & $\mathbf{6}$ & $\mathbf{7}$ & $\mathbf{8}$ & $\mathbf{9}$ & $\mathbf{1 0}$ & $\mathbf{1 1}$ & $\mathbf{1 2}$ & $\mathbf{1 3}$ & $\mathbf{1 4}$ & $\mathbf{1 5}$ & $\mathbf{1 6}$ & $\mathbf{1 7}$ & $\mathbf{1 8}$ & $\mathbf{1 9}$ & $\mathbf{2 0}$ & $\mathbf{2 1}$ & $\mathbf{2 2}$ & $\mathbf{2 3}$ & $\mathbf{2 4}$ \\
\hline 52 & 68 & 84 & 100 & 116 & 132 & 148 & 164 & 180 & 196 & 212 & 228 & 244 & 260 & 276 & 292 & 308 & 324 & 340 & 356 & 372 & 388 \\
\hline
\end{tabular}

Figure 1: Payoff Tables for Workers and Managers in Fixed Wage and Profit Sharing Treatments

The second treatment variation is whether workers are able to report co-workers to the manager for shirking, and thus potentially supplement the noisy signal that the manager receives about individual worker efforts.

In all treatments, the workers see the effort levels of each of their co-workers. In the treatments without reporting, the workers cannot communicate this information to the manager. In the reporting treatments, workers can report zero, one, or both of their co-workers

\footnotetext{
${ }^{6}$ We note that these payoffs mirror those in many linear voluntary contribution mechanism experiments. For instance, a four person public goods game with a marginal per capita return between 0.4 and 0.5 (two of the most common parametrizations in the experimental public goods literature) would produce the same ratio of payoffs under the Nash outcome to payoffs at the social optimum.
} 
to the manager for having put in "low effort." As in the treatments without reporting, the manager sees a screen listing each worker and whether or not they have been flagged while he or she chooses whether to fine any of the workers. In the reporting treatments, the manager also sees whether the worker has been reported by 0,1 , or 2 co-workers.

We chose to keep the noisy "flags" and the co-worker reports separate on the manager's screen, instead of incorporating the reports into the probability that a worker is flagged, to ensure that the managers in the reporting treatments get all of the same information as the managers in the no-reporting treatments, plus the reports, and can interpret the reports as they see fit. We view this as more natural since a manager should know whether she suspects a worker is shirking based on her own experience or based on reports from the worker's peers, and it means the manager unambiguously receives more information when reporting is available.

It costs the worker $\mathrm{E} \$ 5$ for each report he or she sends about a co-worker. The cost of reporting an effort was chosen to be significant to the worker (the same as the cost of exerting an extra unit of effort) but small relative to the $\mathrm{E} \$ 20$ fine that the co-worker would receive if the report convinces the manager to punish. We allow workers to define for themselves which effort levels qualify as "low effort" and also allow workers to be untruthful in their reports, so that participants can use the reporting mechanism however they see fit.

Given our experimental parameterization of the model presented in Section 2, without any reciprocal motivation, we do not expect treatment differences. Since fining is costly and the number of periods is common knowledge, the unique subgame perfect Nash equilibrium is for managers to never fine and for workers to exert the minimal effort of 1 unit. Likewise, reporting collapses because it is costly to do and the benefits are diffuse. The same is true of profit sharing: because workers only receive $12 \%$ of their marginal productivity of 25 , the marginal benefit of working is still smaller than the marginal cost and workers still have a dominant strategy to exert minimal effort. Further, even if managers did choose to fine workers whenever they were flagged, the relationship between the flag and effort is too weak to incentive workers to increase their effort: the marginal cost of effort is 5 while the marginal benefit is a $3 \%$ reduction in the probability of being fined $\mathrm{E} \$ 20$. With reciprocal preferences, however, treatment differences should arise as described in Section 2. If correct, the model suggests that sharing can have another effect: it can motivate peer workers to report each other because the 
shirking of worker $j$ implicitly imposes a cost on worker $i$. With this additional information managers can better target shirking and effort should respond in equilibrium. In other words, the model suggests that with reciprocity among peers the largest efforts should appear in the Profit Sharing \& Peer Reporting treatment.

\section{Results}

\subsection{Effort Provision}

We begin by considering the primary choice of interest: the workers' provision of effort across the four treatments. Figure 2 presents the average effort chosen in each treatment, with bars depicting the $95 \%$ confidence intervals, and indicates a clear ordering of effort choices. Effort is lowest in the baseline, Fixed Wage treatment (FW), where the mean chosen effort is close to 2 (recall that 1 is the minimum). Surprisingly, effort is somewhat higher in the Fixed Wage and Peer Reporting (FW\&PR) treatment, even though workers in this treatment have little incentive to report their co-workers. Profit sharing incentives increase effort further, to around 3.8. Finally, and in line with our predictions, effort is highest when Profit Sharing is combined with Peer Reporting (PS\&PR), with mean chosen effort close to five.

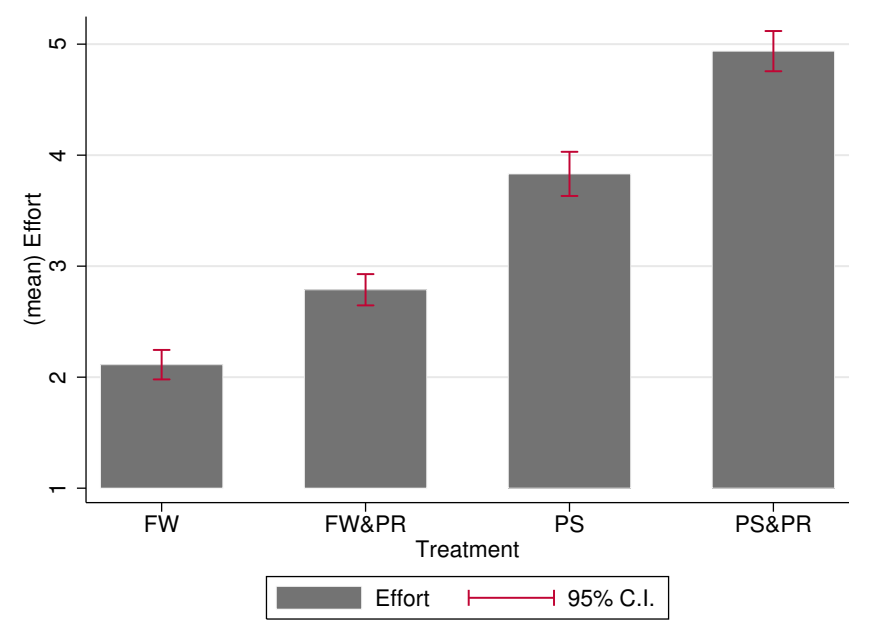

Figure 2: Average effort in each treatment. (Note: 1 is the minimum effort level.)

Next, we consider how effort levels change over time. Figure 3 graphs the average effort chosen in each period, by treatment. Included in the figure are the data from the initial five 
practice periods, in which all subjects experienced the FW treatment. First, we note that effort provision in the practice periods is similar across treatments and declines over time. If anything, effort in the PS\&PR treatment is lowest by the end of the practice rounds, suggesting that our main result is not driven by initial firm interactions or a failure to randomize across treatments. The one exception is the FW\&PR treatment, where effort holds steady at just over 3 across all of the practice periods.

In the main experiment (periods 1 through 10), we observe that the same rank order observed in Figure 2 holds across all periods: effort is low in FW, slightly higher in FW\&PR, higher still in PS, and the highest in PS\&PR. However, effort in the FW\&PR treatment quickly collapses over time and is similar to effort under FW by the end of the session, suggesting that the higher than baseline effort observed in Figure 2 may have been a holdover from higher efforts chosen in the practice rounds and not sustainable. In fact, effort declines significantly over time in all treatments except PS\&PR, where the correlation between period and effort is insignificantly positive. ${ }^{7}$

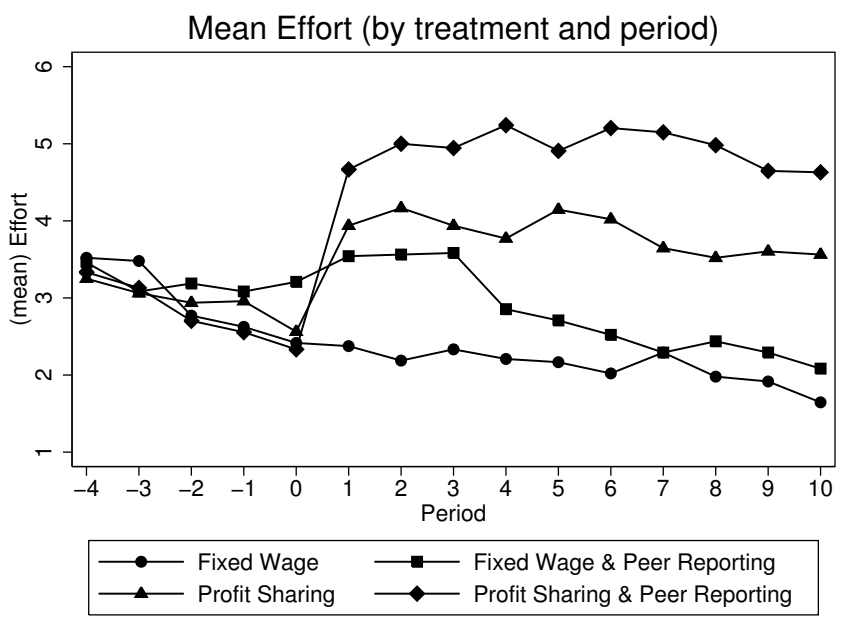

Figure 3: Effort over time. (Note: Periods -4 to 0 are unpaid practice periods in the FW baseline.)

The regression estimates presented in Table 1 provide statistical confirmation of the results shown in Figures 2 and 3. In each model, we regress chosen effort on indicators for the treatments, with the baseline FW treatment serving as the omitted condition. Below each of

\footnotetext{
${ }^{7}$ The Spearman correlations between period and effort are: $\rho=-.123, p<.01(\mathrm{FW}) ; \rho=-.321, p<.01$ $(\mathrm{FW} \& \mathrm{PR}) ; \rho=-0.094, p=.04(\mathrm{PS}) ; \rho=0.009, p=.83(\mathrm{PS} \& \mathrm{PR})$.
} 
the coefficient estimates, we further provide the difference in the coefficients on PS\&PR and PS, as well as between PS and FW\&PR.

Table 1: Effort treatment effects

\begin{tabular}{|c|c|c|c|c|c|}
\hline & (1) & $(2)$ & $(3)$ & $(4)$ & $(5)$ \\
\hline \multirow[t]{2}{*}{ Fixed Wage \& Peer Reporting (I) } & $0.675^{* * *}$ & $0.675^{* *}$ & $0.675^{* *}$ & $0.612^{* *}$ & 0.328 \\
\hline & $(0.099)$ & $(0.403)$ & $(0.294)$ & $(0.251)$ & $(0.279)$ \\
\hline \multirow[t]{2}{*}{ Profit Sharing (I) } & $1.719^{* * *}$ & $1.719^{* * *}$ & $1.719^{* * *}$ & $1.721^{* * *}$ & $1.701^{* * *}$ \\
\hline & $(0.122)$ & $(0.403)$ & $(0.359)$ & $(0.353)$ & $(0.423)$ \\
\hline \multirow[t]{2}{*}{ Profit Sharing \& Peer Reporting (I) } & $2.825^{* * *}$ & $2.825^{* * *}$ & $2.825^{* * *}$ & $2.864^{* * *}$ & $2.968^{* * *}$ \\
\hline & $(0.114)$ & $(0.392)$ & $(0.397)$ & $(0.372)$ & $(0.403)$ \\
\hline \multirow[t]{2}{*}{ Effort in Practice Periods (group mean) } & & & & 0.260 & 0.108 \\
\hline & & & & $(0.172)$ & $(0.182)$ \\
\hline \multirow[t]{2}{*}{ Constant } & $2.113^{* * *}$ & $2.113^{* * *}$ & $2.113^{* * *}$ & $1.343^{* * *}$ & $1.650^{* * *}$ \\
\hline & $(0.068)$ & $(0.285)$ & $(0.204)$ & $(0.504)$ & $(0.543)$ \\
\hline \multirow[t]{2}{*}{ Estimate of (PS\&PR - PS) } & $1.106^{* * *}$ & $1.106^{* * *}$ & $1.106^{* *}$ & $1.143^{* *}$ & $1.267^{* *}$ \\
\hline & $(0.137)$ & $(0.392)$ & $(0.451)$ & $(0.454)$ & $(0.517)$ \\
\hline \multirow[t]{2}{*}{ Estimate of (PS - FW\&PR) } & $1.044^{* * *}$ & $1.044^{* *}$ & $1.044^{* * *}$ & $1.109^{* * *}$ & $1.373^{* * *}$ \\
\hline & $(0.124)$ & $(0.403)$ & $(0.364)$ & $(0.368)$ & $(0.437)$ \\
\hline Errors clustered at group level & No & No & Yes & Yes & Yes \\
\hline Observations collapsed to group means & No & Yes & No & No & No \\
\hline Final five periods only & No & No & No & No & Yes \\
\hline Observations & 1980 & 66 & 1980 & 1980 & 990 \\
\hline$R^{2}$ & 0.248 & 0.491 & 0.248 & 0.259 & 0.29 \\
\hline
\end{tabular}

Notes: The dependent variable is effort choice; ${ }^{*} \mathrm{p}<0.10,{ }^{* *} \mathrm{p}<0.05,{ }^{* * *} \mathrm{p}<0.01$.

The first column includes each worker's effort choice as an independent observation and confirms the ordering of efforts described above: all three treatments generate significantly higher effort than the baseline Fixed Wage condition, with PS significantly higher than FW\&PR and PS\&PR significantly higher than PS. To confirm that our results are robust, we next treat 
each "firm" of three workers and a manager as a single observation averaging across the ten periods $(\mathrm{N}=66)$, and find the same significant treatment differences (Col. 2). Cols. (3) and (4) demonstrate that the same results hold when clustering standard errors at the "firm" level (Col. 3) and when also controlling for average firm effort in the initial practice rounds (Col. 4). As this approach has become the standard practice in experimental economics when the number of clusters is sufficiently large, we continue to cluster the standard errors at the firm level throughout the remainder of the paper. Finally, Col. (5) replicates Col. (4) using only the final 5 periods of the experiment. These estimates confirm the results seen in Figure 3 that, by the end of the session, peer reporting does not increase effort when wages are fixed but does when profits are shared.

\subsection{Reporting and Fining}

We next turn to the two tools available to participants to induce higher effort in their firm: peer reporting and manager fining. Figure 4 shows the average number of peer reports sent to the manager about a worker in a given period, broken down by the worker's effort in the period and whether the treatment was FW\&PR or PS\&PR. First, we see that, as expected, workers are more likely to pay to report their peers when profits are shared. For all effort levels except for one $($ effort $=6)$, more peer reports are sent in the PS\&PR treatment than in the FW\&PR treatment. The figure further suggests that the number of reports sent about a worker is strongly associated with that worker's effort, especially when profits are shared. ${ }^{8}$

The regression estimates in Table 2 further consider the determinants of reporting. The dependent variable is the number of reports sent about a worker. The first column indicates that the reports a worker receives is strongly associated with the worker's effort. Next, we see (Col. 2) that reporting is more common when profits are shared $(\mathrm{p}=.055)$. However, as we saw in section 4.1, effort is also much higher when profits are shared and, since we know from Col. (1) that peers are more likely to report shirkers, the effect of profit sharing on the frequency of reporting might not be fully captured without controlling for the target's effort.

\footnotetext{
${ }^{8}$ While it may seem strange that there were occasional reports of high effort workers (effort $=7$ or 8 ) in the PS\&PR treatment but not in the FW\&PR treatment, we note that efforts of 7 or 8 in the FW\&PR treatment were extremely rare (occurring in only 5 out of 480 observations) but common in the PS\&PR treatment (occurring in over a quarter of observations).
} 


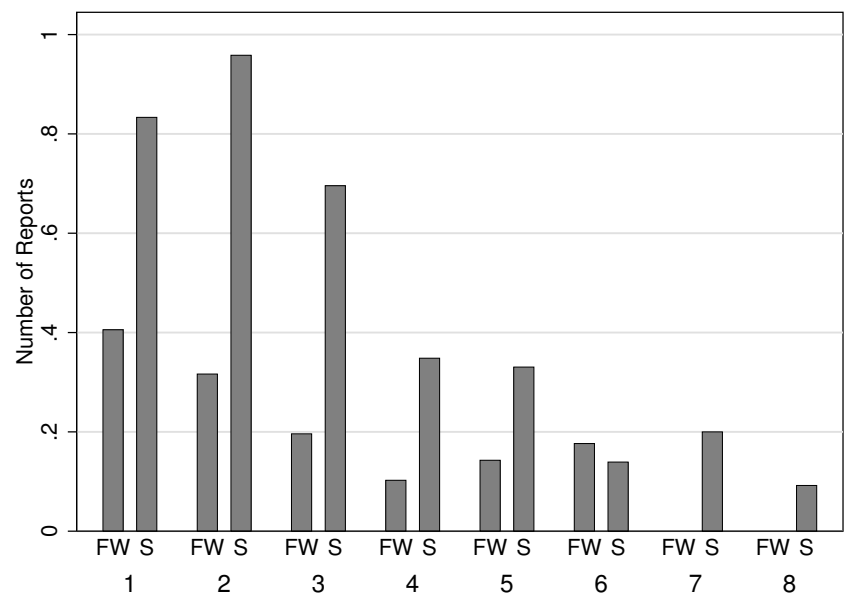

Figure 4: Reports by Worker Effort and Profit Sharing. (Note: FW indicates the FW\&PR treatment while $\mathrm{S}$ indicates the PS\&PR treatment.)

Col. (3) and Col. (4) control for the worker's effort (and the interaction of effort and sharing) and indicate that reporting is more frequent when workers share in the firm's profits. Finally, recall that the initial effort levels in the FW\&PR treatment were not sustainable and that effort collapsed to the baseline FW levels toward the end of the session. To determine whether reporting similarly collapses in the FW\&PR treatment, Col. (5) considers only the final five periods. Toward the end of the session, we observe that reporting is both far more frequent and more responsive to effort when there are profit-sharing incentives. In fact, there is no significant correlation between a worker's effort and whether he was reported in the final half of the FW\&PR treatment. Thus, the results largely confirm the predictions of Section 2. While we do see some peer reporting when wages are fixed (when the model predicts we should not), we find that profit sharing generates significantly more reporting and that, by the end of the experiment, those reports provide a significantly clearer signal to the managers about which workers are shirking. 
Table 2: Determinants of Reporting

\begin{tabular}{lccccc}
\hline & $(1)$ & $(2)$ & $(3)$ & $(4)$ & $(5)$ \\
\hline Worker's Effort & $-0.063^{* * *}$ & & $-0.100^{* * *}$ & $-0.069^{* * *}$ & -0.029 \\
& $(0.015)$ & & $(0.019)$ & $(0.025)$ & $(0.030)$ \\
Profit Sharing (I) & & $0.107^{*}$ & $0.321^{* * *}$ & $0.476^{* * *}$ & $0.626^{* * *}$ \\
& & $(0.054)$ & $(0.081)$ & $(0.180)$ & $(0.219)$ \\
Effort $\times$ Sharing & & & & -0.044 & $-0.094^{* *}$ \\
& & & & $(0.036)$ & $(0.044)$ \\
Constant & $0.559^{* * *}$ & $0.254^{* * *}$ & $0.532^{* * *}$ & $0.448^{* * *}$ & $0.262^{* * *}$ \\
& $(0.074)$ & $(0.024)$ & $(0.065)$ & $(0.081)$ & $(0.080)$ \\
\hline Observations & 1020 & 1020 & 1020 & 1020 & 510 \\
$R^{2}$ & 0.06 & 0.01 & 0.12 & 0.12 & 0.15 \\
\hline
\end{tabular}

Notes: The dependent variable is the number of reports by peer workers.

Standard errors clustered at the group level; * $\mathrm{p}<0.10$, ** $\mathrm{p}<0.05$, *** $\mathrm{p}<0.01$.

We next consider the factors that determine whether a manager chooses to fine her workers, including whether the manager takes into account the reports of co-workers. Table 3 estimates a series of linear probability models, in which the dependent variable is equal to 1 if the worker is fined in the current period. The first model (Col. 1) demonstrates that, across all treatments, the likelihood a worker is fined is significantly associated with his effort level: an increase in effort by one unit decreases the likelihood of being fined by over six percentage points. The fining is more responsive to worker effort than we would expect if the manager were simply fining all flagged workers, in which case we would expect the likelihood of being fined would decrease by 0.03 for each unit of effort. Next, we consider whether fining becomes more accurate when peer reporting is possible. The second model (Col. 2) adds an indicator for whether peer reporting is available and the interaction of peer reporting and the worker's effort. When reporting is available, managers both become more likely to fine workers overall and the likelihood of being fined is more responsive to the worker's actual effort. This confirms the prediction from Section 2 that $p_{e}$ (the first derivative of the fine probability with respect to effort) becomes more negative when reporting is possible. The final two models introduce a 
regressor for the number of peer reports the worker received, to determine whether managers take the peer reports into account and whether these reports drive the differences in the peer reporting treatments indicated by Col. (2). The third model (Col. 3) uses only the data from the two reporting treatments and indicates that these managers rely heavily on worker's reports to choose whether to fine. In the reporting treatments, managers are significantly more likely to fine workers who have been reported by their peers. On average, workers in these treatments who were not reported are fined approximately $23 \%$ of the time, while those who receive one report (two reports) are fined 61\% (91\%) of the time. Finally, the fourth model (Col. 4) reproduces Col. (2) with the inclusion of the reports variable and demonstrates that the effects of peer reporting indicated by Col. (2) come entirely through the number of peer reports the worker received, rather than any other features of the peer reporting treatments.

Table 3: Determinants of Fines

\begin{tabular}{lcccc}
\hline & $(1)$ & $(2)$ & $(3)$ & $4)$ \\
\hline Worker's Effort & $-0.078^{* * *}$ & $-0.055^{* * *}$ & & $-0.055^{* * *}$ \\
& $(0.008)$ & $(0.011)$ & & $(0.011)$ \\
Reporting (I) & & $0.164^{*}$ & & 0.007 \\
& & $(0.096)$ & & $(0.103)$ \\
Effort $\times$ Reporting & & $-0.044^{* *}$ & & -0.026 \\
& & $(0.018)$ & & $(0.018)$ \\
Reports & & & $0.357^{* * *}$ & $0.282^{* * *}$ \\
& & & $(0.036)$ & $(0.037)$ \\
Constant & $0.641^{* * *}$ & $0.565^{* * *}$ & $0.230^{* * *}$ & $0.565^{* * *}$ \\
& $(0.046)$ & $(0.049)$ & $(0.042)$ & $(0.049)$ \\
\hline Observations & 1980 & 1980 & 1020 & 1980 \\
$R^{2}$ & 0.12 & 0.13 & 0.18 & 0.19 \\
\hline
\end{tabular}

Notes: The dependent variable is 1 if the Worker is fined.

Standard errors clustered at group level; ${ }^{*} \mathrm{p}<0.10,{ }^{* *} \mathrm{p}<0.05, * * * \mathrm{p}<0.01$.

We conclude this subsection by considering how the frequency and accuracy of fines vary across each of our four conditions. The linear probability models estimated in Table 4 regress 
whether the subject was fined on treatment indicators, with the baseline FW condition serving as the omitted condition. Without controlling for worker effort (Col. 1), we see significant differences in the likelihood of being fined across treatments. While workers in the FW condition are fined nearly half of the time (47\%), the likelihood of being fined shrinks to $34 \%$ in the PS treatment and $27 \%$ in the PS\&PR treatment. Once we control for effort, however, there are no longer any differences in the amount of fines issued by managers across our four treatments (Col. 2).

However, it may be that fines are more precisely targeted in some treatments. Thus the dependent variable in the final two models is an indicator that is equal to 1 if a worker is fined in a period in which he put in low effort ( 4 or lower) or not fined in a period in which he put in high effort (5 or higher). ${ }^{9}$ From Col. (3), we see that workers in the FW treatment are fined (or escape unfined) accurately less than half of the time. While the likelihood of being fined accurately is not significantly higher in either the FW\&PR treatment or the PS treatment, workers in the PS\&PR treatment are far more likely to be fined accurately. The final model demonstrates that, while high effort workers are more likely to be accurately fined (i.e. go unfined when they should), the results are similar when controlling for effort.

\footnotetext{
${ }^{9}$ Instead of dividing the strategy space in half to define low and high effort, if we break effort at the observed median instead the results reported in Tables 4 and 5 are substantively unchanged.
} 
Table 4: Fines by Treatment

\begin{tabular}{lcccc}
\hline & $(1)$ & $(2)$ & $(3)$ & $(4)$ \\
\hline Fixed Wage \& Peer Reporting (I) & -0.044 & 0.010 & 0.027 & -0.002 \\
& $(0.072)$ & $(0.078)$ & $(0.075)$ & $(0.075)$ \\
Profit Sharing (I) & $-0.133^{* *}$ & 0.004 & 0.067 & -0.007 \\
& $(0.065)$ & $(0.069)$ & $(0.062)$ & $(0.060)$ \\
Profit Sharing \& Peer Reporting (I) & $-0.202^{* * *}$ & 0.023 & $0.263^{* * *}$ & $0.142^{* *}$ \\
& $(0.069)$ & $(0.078)$ & $(0.062)$ & $(0.069)$ \\
Worker's Effort & & $-0.08^{* * *}$ & & $0.043^{* * *}$ \\
& & $(0.010)$ & & $(0.011)$ \\
Constant & $0.469^{* * *}$ & $0.637^{* * *}$ & $0.485^{* * *}$ & $0.395^{* * *}$ \\
& $(0.049)$ & $(0.057)$ & $(0.047)$ & $(0.053)$ \\
\hline Observations & 1980 & 1980 & 1980 & 1980 \\
$R^{2}$ & 0.03 & 0.12 & 0.05 & 0.07 \\
\hline
\end{tabular}

Notes: (1) \& (2): the dependent variable is 1 if the Worker is fined;

(3) \& (4) the dependent variable is 1 if the Worker is fined (or not fined) accurately.

Standard errors clustered at group level; * $\mathrm{p}<0.10,{ }^{* *} \mathrm{p}<0.05,{ }^{* * *} \mathrm{p}<0.01$.

\subsection{Response to Fines}

To summarize the results of the previous subsection, we have seen that workers in the PS\&PR treatment are more likely to report their co-workers and more likely to do so accurately, that managers rely heavily on peer reports in choosing whether to fine a worker, and that fines are doled out with significantly more accuracy in the PS\&PR treatment than in any other condition. Taken together, the results thus far strongly indicate that workers who receive a share of firm profits are willing to engage in costly reporting to direct the manager's fines at shirking co-workers.

However, the accurate direction of fines discussed in the previous subsection is only beneficial if shirkers actually increase their efforts in response. Therefore, we next consider how workers respond to being fined. Table 5 presents the estimates of regressions of a worker's current effort on an indicator for whether he was fined by his manager in the previous period 
and the effort he chose in the previous period. In Col. (1), we see that the workers' efforts are strongly correlated with their choices in the previous period but that punishment has no effect on their choice.

Table 5: Response to Fines

\begin{tabular}{|c|c|c|c|c|}
\hline & (1) & $(2)$ & $(3)$ & $(4)$ \\
\hline & All & Low Effort & High Effort & All \\
\hline \multirow[t]{2}{*}{ Fined Last Period (I) } & 0.014 & $0.260^{* *}$ & $-0.879 * * *$ & $-0.403^{* * *}$ \\
\hline & $(0.097)$ & $(0.112)$ & $(0.193)$ & $(0.118)$ \\
\hline \multirow[t]{2}{*}{ Effort Last Period } & $0.719^{* * *}$ & $0.729^{* * *}$ & $0.697^{* * *}$ & $0.703^{* * *}$ \\
\hline & $(0.032)$ & $(0.050)$ & $(0.113)$ & $(0.033)$ \\
\hline \multirow[t]{2}{*}{ Fined Last Period x FW\&PR } & & & & $0.290 * *$ \\
\hline & & & & $(0.141)$ \\
\hline \multirow[t]{2}{*}{ Fined Last Period x PS } & & & & $0.474^{* *}$ \\
\hline & & & & $(0.212)$ \\
\hline \multirow[t]{2}{*}{ Fined Last Period x PS\&PR } & & & & $1.029^{* * *}$ \\
\hline & & & & $(0.229)$ \\
\hline \multirow[t]{2}{*}{ Constant } & $0.913^{* * *}$ & $0.780^{* * *}$ & $1.19^{* * *}$ & $0.976^{* * *}$ \\
\hline & $(0.124)$ & $(0.141)$ & $(0.663)$ & $(0.129)$ \\
\hline Observations & 1782 & 1209 & 573 & 1782 \\
\hline$R^{2}$ & 0.50 & 0.28 & 0.23 & 0.51 \\
\hline
\end{tabular}

Notes: The dependent variable is effort.

Standard errors clustered at group level; ${ }^{*} \mathrm{p}<0.10,{ }^{* *} \mathrm{p}<0.05,{ }^{* * *} \mathrm{p}<0.01$.

However, workers may respond differently depending on whether the fine was "justified." The second column presents results of the same regression model including only "low effort" workers, who chose an effort of 4 or lower in the previous period. We see that the fine has a significant positive effect on effort for these workers. For "high effort" workers, however, the fining strongly backfires: $\mathrm{Col}$ (3) indicates that workers who were already choosing effort levels of 5 or higher decrease their effort by 0.88 units following a fine. Therefore, the accurate direction of fines toward those workers who are shirking can benefit productivity through two separate 
channels: by increasing the efforts of shirkers and by ensuring that frustrated managers don't inadvertently trigger a backlash among hard workers by fining indiscriminately. The implication that fines are used successfully only in the PS\&PR condition is confirmed by Col. (4) in Table 5. From these estimates, we observe that, controlling for effort, FW workers who were fined in the previous period significantly decrease their effort by 0.4 units in the subsequent period, FW\&PR and PS workers do not significantly alter their efforts, and workers in the PS\&PR treatment increase their efforts by 0.63 units.

\subsection{Overall Firm Outcomes}

Finally, we consider whether implementing a profit-sharing system is ultimately profitable for the firm. While we have found that profit-sharing increases effort, the firm only sees $64 \%$ of the return on that effort, with the workers collectively taking in $36 \%$ of the firm profits.

We first consider the extent to which the managers benefit from the profit sharing arrangement. The first two columns of Table 6 report estimates of an OLS regression of manager earnings on the treatment indicators, for either all ten periods (Col. 1) or the final five periods of the experiment (Col. 2). Recall that the manager's profit is equal to 100 plus the manager's share of the firm's profit (100\% in fixed wage treatments and $64 \%$ in profit sharing treatments) minus any costs of fining workers. We observe that the manager's rank order profits are identical to that of effort, with FW\&PR and PS both generating more profits than just fixed wage and the PS\&PR generating significantly higher profits than any other condition. In other words, managers strongly benefit from the profit sharing incentives - especially when workers can report their peers. Note that the coefficient on FW (the constant) is 101, indicating that the average manager payoff just barely exceeds the base wage of 100 . We further note that the results are similar if we focus on the final half of the experiment, except that FW\&PR no longer generates higher manager payoffs than the FW condition. As we saw in Section 4.2, fining is more common when wages are fixed and, since fining is costly, it is important to check whether inefficient fining is driving the treatment differences we see here. The dependent variable in Cols. (3) and (4) is thus the manager's profit before the cost of issuing fines and the estimates are nearly identical to those in Cols. (1) and (2). 
Table 6: Overall Firm Outcomes

\begin{tabular}{lcccccc}
\hline & $(1)$ & $(2)$ & $(3)$ & $(4)$ & $(5)$ & $(6)$ \\
\hline Fixed Wage \& Peer Reporting (I) & $51.28^{* *}$ & 24.81 & $50.62^{* *}$ & 26.56 & $0.069^{* *}$ & 0.016 \\
& $(22.12)$ & $(21.70)$ & $(22.12)$ & $(21.82)$ & $(0.032)$ & $(0.031)$ \\
Profit Sharing (I) & $81.46^{* * *}$ & $82.76^{* * *}$ & $79.46^{* * *}$ & $82.39^{* * *}$ & $0.195^{* * *}$ & $0.179^{* * *}$ \\
& $(21.06)$ & $(23.60)$ & $(20.88)$ & $(23.38)$ & $(0.040)$ & $(0.048)$ \\
Profit Sharing \& Peer Reporting (I) & $135.57^{* * *}$ & $145.27^{* * *}$ & $132.54^{* * *}$ & $142.45^{* * *}$ & $0.309^{* * *}$ & $0.322^{* * *}$ \\
& $(22.75)$ & $(23.24)$ & $(22.40)$ & $(22.99)$ & $(0.046)$ & $(0.047)$ \\
Constant & $101.41^{* * *}$ & $91.94^{* * *}$ & $108.44^{* * *}$ & $97.81^{* * *}$ & $0.330^{* * *}$ & $0.326^{* * *}$ \\
& $(15.23)$ & $(14.76)$ & $(15.30)$ & $(14.95)$ & $(0.021)$ & $(0.020)$ \\
\hline Estimate of (PS\&PR - PS) & $54.11^{* *}$ & $62.51^{* *}$ & $53.08^{* *}$ & $60.07^{* *}$ & $0.114^{* *}$ & $0.143^{* *}$ \\
& $(22.30)$ & $(25.71)$ & $(21.67)$ & $(25.06)$ & $(0.052)$ & $(0.060)$ \\
Estimate of (PS - FW\&PR) & 30.18 & $57.95^{* *}$ & 28.84 & $55.83^{* *}$ & $0.126^{* * *}$ & $0.163^{* *}$ \\
& $(21.66)$ & $(24.33)$ & $(21.38)$ & $(23.98)$ & $(0.041)$ & $(0.049)$ \\
\hline Final five periods only & No & Yes & No & Yes & No & Yes \\
\hline
\end{tabular}

Notes: The dependent variable is manager profit or efficiency.

Standard errors clustered at group level; * $\mathrm{p}<0.10,{ }^{* *} \mathrm{p}<0.05,{ }^{* * *} \mathrm{p}<0.01$.

To conclude, we consider the overall outcomes, not only for the managers, but for the entire firm. In all treatments, the highest total profits that could be earned collectively by the four-member firm is 580 . We define firm efficiency as the sum of worker and manager profits divided by 580 and use this as the dependent variable in models (5) and (6) of Table 6. Once more, we find that efficiency is substantially higher in both of the profit sharing treatments and that it is at its highest when reporting and sharing interact. In the final five periods efficiency is less than $1 / 3$ in the $\mathrm{FW}$ baseline, similar in FW\&PR, close to $1 / 2$ in PS and close to $2 / 3$ in PS\&PR. 


\section{Discussion}

Economists have long been puzzled by the positive effect of profit sharing incentives on worker productivity, which occurs despite the relatively small pecuniary return on effort for any individual worker. One explanation, which has received attention in various forms in the literature, is that profit sharing motivates workers, who are better informed about their co-workers' behavior, to enforce higher effort in a way that the management alone cannot (Kandel and Lazear, 1992; Freeman et al., 2010). This enforcement can take the form of implicit social pressure, direct confrontation, or simply passing along more accurate reports about team members to the manager. While survey evidence finds that workers in firms with shared capitalism monitor peers more closely and are more likely to take action against shirkers (Welbourne, 1995; Freeman et al., 2010), these surveys cannot speak to the causal effect of profit sharing on worker behavior.

We contribute a controlled laboratory test of this explanation, which allows us to isolate the impact of profit sharing alone and the impact of the channel through which it is hypothesized to work: whether workers can use their onsite information to assist management in enforcing high productivity. To do so, we set up a workplace experiment where workers' on-the-ground information about co-worker productivity could play a role. Workers choose how much costly effort to exert for a fixed wage, while managers have only a very weak signal of individual worker effort to use when choosing whether to disclipline workers. We independently vary the inclusion

of profit sharing incentives and whether workers can supplement the manager's otherwise noisy signals of individual output by reporting shirkers to their manager. By varying only whether information can be transmitted from workers to manager, we are able to fully isolate the effect of worker willingness to act on their superior information, without simultaneously manipulating other factors such as social pressure or direct peer punishment. Further, we allow workers themselves to establish a workplace norm and develop their own criteria for when a co-worker should be reported to the manager, and we allow the manager to interpret the reports of her workers and dole out punishments as she sees fit.

We find evidence that profit sharing incentives alone do increase worker effort somewhat, a finding that is consistent with heterogeneous effort costs, perhaps due to differing intrinsic 
motivation or social preferences of workers. More markedly, we find that effort is significantly higher when the firm offers profit sharing and workers have the ability to supplement the manager's otherwise noisy information by reporting their peers. Peer reporting alone cannot sustain effort when workers do not share in the profits, strongly supporting our hypothesis that profit sharing "turns on" an otherwise untapped mechanism for promoting firm productivity. In addition, both workers and the firm management earn significantly higher payoffs when profits are shared with workers who can report their peers.

Our results therefore suggest that profit sharing is likely to be most successful when channels exist for workers to share information about co-worker productivity with management. We find clear evidence that workers who share in profits are more willing to accurately supplement their managers' information. In turn, managers rely heavily on worker reports when doling out punishments and, as a result, punishments are directed toward shirkers with significantly greater accuracy in the treatment with both profit sharing and peer reporting. Completing the successful chain of events, shirkers who were punished significantly increase their effort in the subsequent period. Interestingly, we find an additional benefit to the manager being able to direct punishment toward those who were actually shirking: workers who exerted high effort and yet were still hit with punishment sharply decrease their effort in the subsequent period. Thus, being able to determine which workers were shirking allows the manager to avoid indiscrimately punishing the entire team, an action which strongly backfires in our environment.

\section{Appendix - Experimental Instructions}

Hello and welcome to our experiment. Please follow along with these instructions as I read them aloud.

Payment and Confidentiality

You will be taking part in an experiment studying interactions within an office environment. You will play multiple periods of the same decision-making game. In addition to the $\$ 5$ that you will be paid for showing up, you have the opportunity to earn an additional amount of money based on your decisions if you follow these instructions carefully. 
You will be grouped with three other participants in the room and randomly assigned the role of either a Worker or a Manager such that each group has exactly 3 Workers and 1 Manager. You will stay in the same role and group for the entire duration of the experiment. During the experiment, earnings will be calculated in terms of experimental dollars and then translated at the end of the experiment into real dollars at the following exchange rate:

250 Experimental Dollars $(\mathrm{E} \$)=\$ 1$ (Managers)

33 Experimental Dollars $(\mathrm{E} \$)=\$ 1$ (Workers)

Please note that any and all decisions that you make or responses that you provide during the experiment are strictly confidential and anonymous. We intend to use the data collected from the study for academic work as it relates to economic decision making. To assure your decisions are confidential, we ask that you do not speak to each other until the entire session ends.

Worker Instructions

If you are a Worker, you will be paid a fixed wage of $\mathrm{E} \$ 50$ in each period. Every period, you have the option to choose how much effort you want to put into your work. Your effort will be a number from 1 unit to 8 units. Effort is costly, and your payoff is the difference between the wage and your cost of providing effort. Specifically, it costs you $\mathrm{E} \$ 5$ for each unit of effort and your earnings would be given by:

Your payoff in $\mathrm{E} \$($ at the end of each period $)=50$ - (Effort $\mathrm{x} 5)$

The table below shows the amount that a Worker would earn for the period, for each possible effort level he or she chose (in $\mathrm{E} \$$ ):

\section{Your Effort}

\begin{tabular}{|r|r|r|r|r|r|r|r|}
\hline $\mathbf{1}$ & $\mathbf{2}$ & $\mathbf{3}$ & $\mathbf{4}$ & $\mathbf{5}$ & $\mathbf{6}$ & $\mathbf{7}$ & $\mathbf{8}$ \\
\hline $\mathbf{4 5}$ & $\mathbf{4 0}$ & $\mathbf{3 5}$ & $\mathbf{3 0}$ & $\mathbf{2 5}$ & $\mathbf{2 0}$ & $\mathbf{1 5}$ & 10 \\
\hline
\end{tabular}

Towards the end of each period, each Worker will be able to see the effort put in by each of his or her peer Workers. The Manager will see the total effort put in, but will not see each individual's effort until the very end of the period. 
Instead, the Manager may see a signal or a "flag" that is weakly related to your effort. After each Worker has chosen his or her effort for the period, the Manager will see a screen, similar to the picture below, listing each of the Workers in the group. A flag may appear beside one or more of the Workers, indicating to the Manager that this Worker may have chosen low effort. The flag appears randomly, but the likelihood that it appears depends on the Worker's effort. Specifically, the probability that the flag appears $=.53-.03$ times Effort. Note, however, that this means that Workers who put in high effort will still sometimes be flagged and that Workers who put in low effort often will not be flagged. The table below shows the possible effort choices and the likelihood that a Worker making that choice will be flagged.

\begin{tabular}{|c|c|c|c|c|c|c|c|c|}
\hline Effort & 1 & 2 & 3 & 4 & 5 & 6 & 7 & 8 \\
\hline \hline Likelihood of Flag & 0.50 & 0.47 & 0.44 & 0.41 & 0.38 & 0.35 & 0.32 & 0.29 \\
\hline
\end{tabular}

For example, if you choose the minimal effort $($ Effort $=1)$, you will be flagged with probability 0.5 (half of the time). If you choose the maximum effort $($ Effort $=8)$, you will be flagged with probability 0.29. For efforts in between, your likelihood of being flagged will be in between these amounts. After viewing this information, the Manager may choose to impose a fine of $\mathrm{E} \$ 20$ on any Worker(s) in the group. The Worker numbers will be randomly reassigned each period, so that participants will not be able to track any individual's choices across periods.

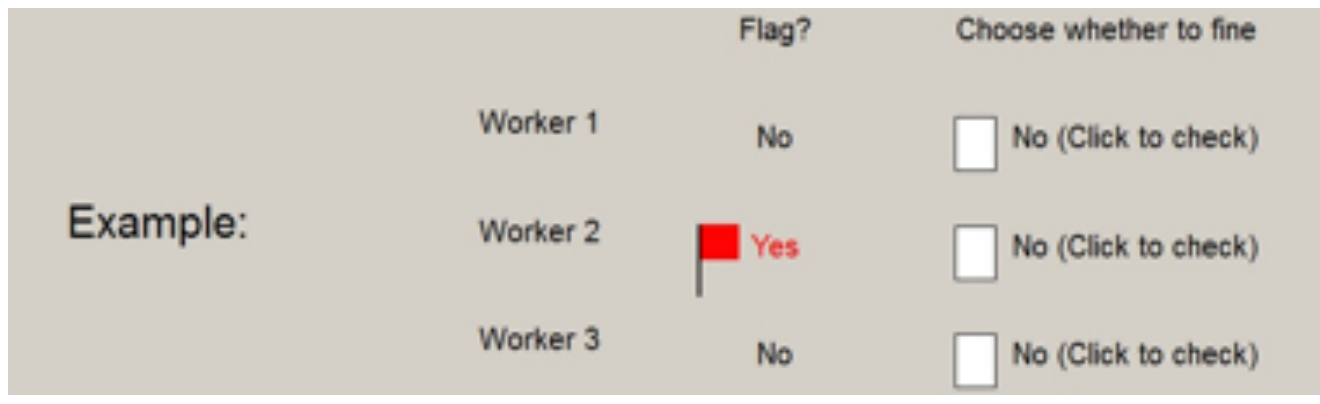

Manager Instructions

If you are a Manager, you will receive a payment of $\mathrm{E} \$ 100$ each period. In addition, you will receive any profits of your firm, which depends on the effort Workers collectively put into work. 
Each unit of effort put in by a Worker increases firm profits by $\mathrm{E} \$ 25$. The firm's profits are therefore equal to 25 times the total effort of all Workers, minus the wages that the Workers receive ( $\mathrm{E} \$ 50$ each). Your payment is thus given by:

Your payoff in $\mathrm{E} \$$ (at the end of each period) $=100+25 \times$ Total sum of Worker effort - (3 Workers) x (Worker wage of 50)

The table below shows your earnings for each TOTAL effort level put in by the Workers in your group. (Recall that Workers' effort levels must be between 1 and 8.)

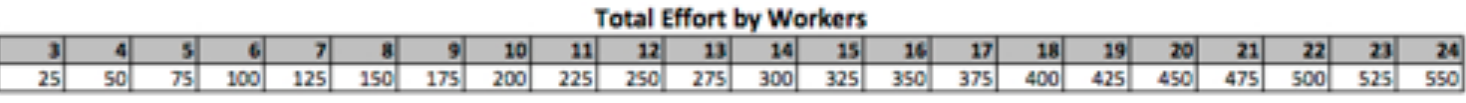

Toward the end of the period you will be shown the total effort provided by your group, but will not see each individual Worker's effort. Instead, you may see flags beside some of the Workers. As described on the previous page, Workers who put in lower effort are more likely to have a flag beside their name - but it is also likely that Workers who chose high effort are wrongly flagged or that Workers who did choose low effort are not flagged. Lastly, you will be able to fine any of the three Workers. The $\mathrm{E} \$ 20$ fine will be deducted from the Worker's payoff for the period and will cost you $\mathrm{E} \$ 5$ for each Worker that you fine.

At the end of the period, after you have chosen whether fine anyone, you will see the actual effort chosen by each Worker. The Worker numbers will be randomly reassigned the following period, so you will not able to track a Worker's choices across periods.

\section{Summary of Instructions}

1) Each Worker independently decides how much effort to put into working.

2) Workers see the effort put in by other Workers in their group. Managers only see the total effort, but may also see a "flag" next to the Workers' ID \#, which is weakly associated with how much effort that Worker chose. 
3) The Manager has the option to fine any of the three Workers. We will now play a 5 period practice round. There will be no payments for these periods, as they are designed to familiarize you with the task before subsequent paid periods. After the practice, additional instructions may be provided before the paid periods begin.

Instructions (Profit Sharing 8 Peer Reporting Treament)

That concludes the practice rounds. The paid periods will now begin. You will play 10 periods with the same group and your role (Manger or Worker) will be the same as in the practice periods. The following change is being made to the instructions: Workers now share in the profits of the firm (including both the return on Worker effort and the cost of paying wages). Recall that the firm's profits are: $25 \mathrm{x}$ (Total Effort) - (3 Workers) x (Wage of 50). Each Worker will receive $12 \%$ of the firm's profits and the Manager will receive the remaining $64 \%$ of the profits. For the Workers, this means that payoffs will now depend on your own effort and on the effort of the two other Workers. Your payoffs in each case are given by the table below.

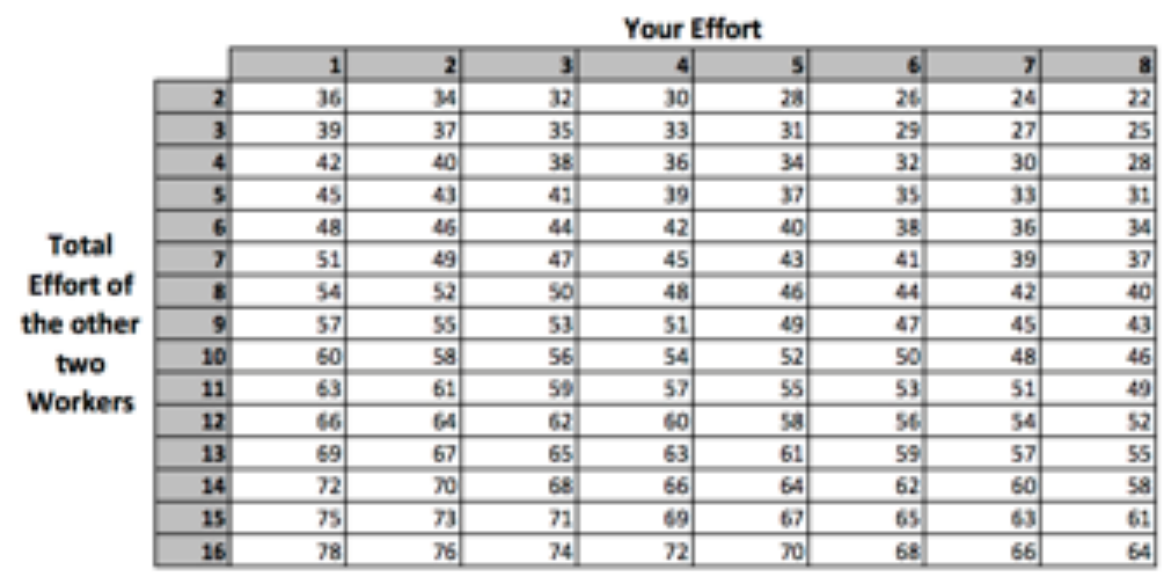

Interpretation of the table: The columns are labeled 1 through 8 along the top of the table and refer to the effort levels you could choose. The rows are labeled 2 through 16 along the left side of the table and refer to the efforts that the other two Workers could choose in total. The cells show the $\mathrm{E} \$$ you would receive in each case. For example, imagine everyone chose effort 4. To find your payoff, we would look in the column marked " 4 " for your effort and in the row marked "8" for the total efforts of the two others. We find that your payoff is $\mathrm{E} \$ 48$. 
Please note:

o As you increase your own effort, your earnings decrease by 2 (we can see this by looking from left to right in any row of the table).

o For each extra unit of effort by one of the other Workers, your earnings increase by 3 (we can see this by looking from top to bottom in any column of the table).

If you are a Manager, you will still receive a payment of $\mathrm{E} \$ 100$ each period. In addition, you will receive $64 \%$ of any profits of your firm. As before, firm profits are given by Firm Profits $=25 \times$ (Total sum of Worker effort) - (3 Workers) $\mathrm{x}$ (Worker wage of 50) Your payoff in $\mathrm{E} \$$ (at the end of each period) $=100+0.64 \times$ Firm Profits The table below shows your earnings for each TOTAL effort level put in by the Workers in your group. (Recall that Workers' effort levels must be between 1 and 8.)

Total Effort by Workers

\begin{tabular}{|r|r|r|r|r|r|r|r|r|r|r|r|r|r|r|r|r|r|r|r|r|r|}
\hline $\mathbf{3}$ & 4 & 5 & 6 & $\mathbf{7}$ & $\mathbf{8}$ & 9 & $\mathbf{1 0}$ & $\mathbf{1 1}$ & $\mathbf{1 2}$ & $\mathbf{1 3}$ & $\mathbf{1 4}$ & $\mathbf{1 5}$ & $\mathbf{1 6}$ & $\mathbf{1 7}$ & $\mathbf{1 8}$ & $\mathbf{1 9}$ & $\mathbf{2 0}$ & $\mathbf{2 1}$ & $\mathbf{2 2}$ & $\mathbf{2 3}$ & $\mathbf{2 4}$ \\
\hline 52 & 68 & 84 & 100 & 116 & 132 & 148 & 164 & 180 & 196 & 212 & 228 & 244 & 260 & 276 & 292 & 308 & 324 & 340 & 356 & 372 & 388 \\
\hline
\end{tabular}

An additional change is also being made to the instructions: Just as in the practice round, Workers will see the effort choices of each Worker in their group toward the end of the period. However, Workers now have the opportunity to "report" one or more of their peer Workers to the Manager for putting in low effort. Just as before, a flag may appear to the Manager, weakly based on the Worker's efforts. If you send a report, it will appear alongside any flag. The picture below shows what the Manager will see. It costs you $\mathrm{E} \$ 5$ for each report that you send to the Manager.

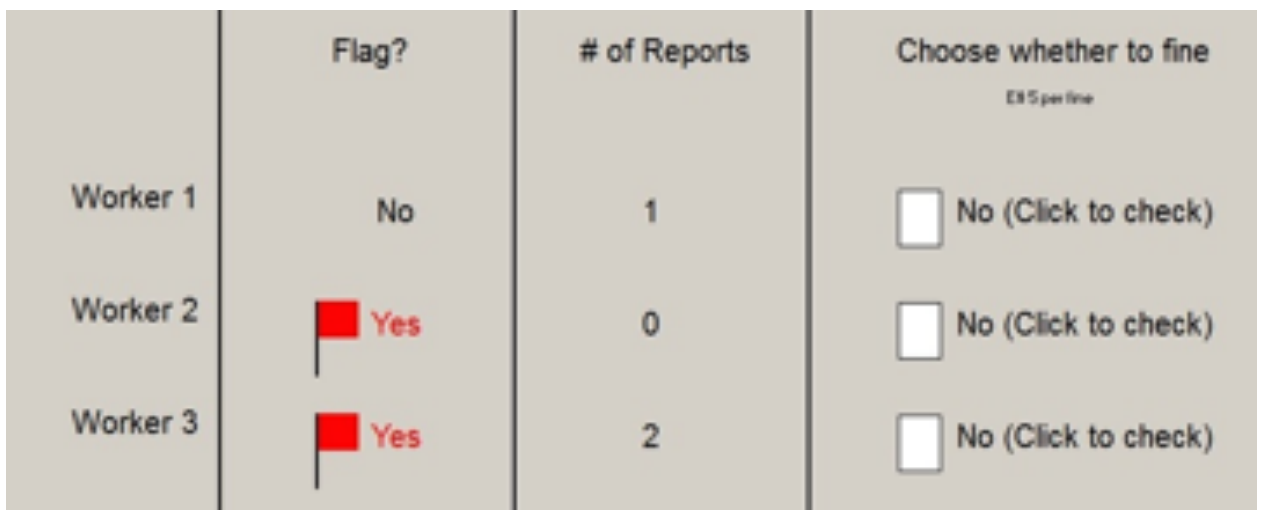


To summarize,

1) Each Worker independently decides how much effort to put into working.

2) Workers see the effort put in by other Workers in their group. Workers can report either or both of their peer Workers to the Manager for low effort. Managers only see the total effort, but may also see a "flag" next to the Workers' ID \#, which is weakly associated with how much effort that Worker chose. They also see how many low effort reports the Worker received from their peer Workers.

3) The Manager has the option to fine any of the three Workers.

\section{$7 \quad$ References}

Akerlof, G., 1982. Labor Contracts as Partial Gift Exchange. Quarterly Journal of Economics, 92(November), 543-569.

Akerlof, G., Kranton, R., 2005. Identity and the Economics of Organizations. Journal of Economic Perspectives, 19(1), 9-32.

Alchian, A., Demsetz, H., 1972. Production, Information Costs, and Economic Organization. American Economic Review, 62(December), 777-795.

Banerjee, A., Besley, T., Guinnane, T., 1994. Thy Neighbor's Keeper: The Design of a Credit Cooperative with Theory and a Test. Quarterly Journal of Economics, 109(May), 491-515.

Benabou, R., Tirole, J., 2003. Intrinsic and Extrinsic Motivation. Review of Economic Studies, 70(3), 489-520.

Besley, T., Coate, S., 1995. Group Lending, Repayment Incentives and Social Collateral. Journal of Development Economics, 46, 1-18.

Bhargava, S., 1994. Profit Sharing and the Financial Performance of Companies: Evidence from U.K. Panel Data. The Economic Journal, 104(426), 1044-1056.

Bowles, S., 1985. The production process in a competitive economy: Walrasian, NeoHobbesian and Marxian models. American Economic Review, 75(1), 16-36.

Carpenter, J., Bowles, S., Gintis, H., Hwang, S.-H., 2009. Strong reciprocity and team production: theory and evidence. Journal of Economic Behavior \& Organization, 71(2), 221- 
232.

Charness, G., Kuhn, P., 2011, Chapter 3 - Lab Labor: What Can Labor Economists Learn from the Lab? In: A. Orley, C. David (Eds.). Handbook of Labor Economics. Elsevier, pp. 229-330.

Chaudhuri, A., 2011. Sustaining cooperation in laboratory public good experiments: a selective survey of the literature. Experimental Economics, 14(1), 47-83.

Corgnet, B., 2012. Peer evaluations and team performance: when friends do worse than strangers. Economic Inquiry, 50(1), 171-181.

Fischbacher, U., 2007. z-Tree: Zurich Toolbox for Ready-made Economic Experiments. Experimental Economics, 10(2), 171-178.

Freeman, R., Kruse, D., Blasi, J., 2010, Worker responses to shirking under shared capitalism. In: D. Kruse, R. Freeman, J. Blasi (Eds.). Shared Capitalism at Work: Employee Ownership, Profit and Gain sharing, and Borad-based Stock Options. University of Chicago Press, Chicago, pp. 77-103.

Hansen, D., 1997. Worker Performance and Group Incentives: a case study. Industrial and Labour Relations Review, 51(1), 37-49.

Holmstrom, B., 1982. Moral Hazard in Teams. Bell Journal of Economics, 13, 324-340.

Kandel, E., Lazear, E., 1992. Peer Pressure and Partnerships. Journal of Political Economy, 100(4), 801-817.

Knez, M., Simester, D., 2001. Firm-wide Incentives and Mutual Monitoring as Continental Airlines. Journal of Labor Economics, 19(4), 743-772.

Rabin, M., 1993. Incorporating Fairness into Game Theory and Economics. American Economic Review, 83(5 December), 1281-1302.

Rotemberg, J.J., 1994. Human Relations in the Workplace. Journal of Political Economy, 102(4), 684-717.

Shapiro, C., Stiglitz, J.E., 1984. Equilibrium Unemployment as a Worker Discipline Device. The American Economic Review, 74(3), 433-444.

Weitzman, M., Kruse, D., 1990, Profit Sharing and Productivity. In: A. Blinder (Ed.). Paying for Productivity: a look at the evidence. Brookings Institution, Washington DC, pp. 95-140. 
Welbourne, T., 1995. Gainshairing and Mutual Monitoring: A Combined AgencyOrganisational Justice Interpretation. the Academy of Management Journal, 38(3), 881-899. 